\title{
Pengembangan Pemasaran untuk Meningkatkan Kinerja Usaha Rakik Azizah di Kota Padang
}

\author{
Ratni Prima Lita, Agriqisty, Hendra Lukito, Yanti, Sari Suya, John Edwar, Laela Susdiani, Valeny \\ Suryaningsih, dan Danny Hidayat \\ Fakultas Ekonomi, Universitas Andalas, Kampus Limau Manis, Padang, 25163. Indonesia \\ E-mail: ratniprimalita@eb.unand.ac.id
}

Keywords: community service, development, marketing, Rakik Azizah

Kata Kunci: pengembangan, pemasaran, Usaha Rakik Azizah

\begin{abstract}
Community Service Activities in Rakik Azizah in Padang City are carried out to identify and solve problems faced by owners in managing and developing Rakik Azizah's. Some of the problems faced by the owner are related to obtaining business licenses, managing business finances, using packaging and marketing. The technique used in carrying out this service activity is through counseling and assistance for the owner of Rakik Azizah. Counseling was carried out during the period the activities were carried out at the Management Department, Universitas Andalas. This extension activity will be followed by demonstration and practice as well as consultation during the period of service to better provide understanding and application of the materials provided in the extension activities that have been carried out. Furthermore, mentoring activities carried out using the vocational method where the community service activity team directly accompanies the operational activities of Rakik Azizah's at the operational location of the business. The activity results are files to administer IPRT, Packaging with attractive labels and increased on line marketing.
\end{abstract}

\begin{abstract}
ABSTRAK
Kegiatan Pengabdian Kepada Masyarakat Pada Usaha Rakik Azizah di Kota Padang dilaksanakan untuk mengidentifikasi dan memecahkan masalah yang dihadapi oleh pemiliki dalam mengelola dan mengembangkan Usaha Rakik Azizah. Beberapa persoalan dihadapi oleh pemilik yang berkaitan dengan pengurusan IPRT, penggunaan kemasan dan pemasarannya. Teknik yang digunakan dalam melaksanakan kegiatan pengabdian ini adalah melalui penyuluhan dan pendampingan bagi pemilik Usaha Rakik Azizah. Penyuluhan dilakukan selama jangka waktu kegiatan dilakukan dilakukan di Jurusan Manajemen, Universitas Andalas. Kegiatan penyuluhan ini akan diikuti dengan peragaan dan praktek serta konsultasi selama jangka waktu pengabdian untuk lebih memberikan pemahaman serta penerapan dari materi-materi yang diberikan didalam kegiatan penyuluhan yang telah dilakukan. Selanjutnya dilakukan kegiatan pendampingan yang dilakukan menggunakan metode vokasi dimana tim kegiatan pengabdian kepada masyarakat secara langsung mendampingi kegiatan operasional Usaha Rakik Azizah di lokasi operasional usaha tersebut. Hasil kegiatan memberikan hasil yaitu, berkas untuk mengurus IPRT, kemasan dengan label yang menarik dan peningkatan pemasaran on line.
\end{abstract}




\section{PENDAHULUAN}

Industri kreatif membuka dampak positif seperti mampu menyumbang terhadap Pendapatan Domestik Bruto, membuka lapangan kerja dan memperkuat ekspor pada sektor usaha industri hulu dan hilir serta mempunyai daya saing tinggi, mempunyai potensi membangun citra dan identitas bangsa. Salah satu industri kreatif adalah industri makanan. Usaha makanan banyak digeluti oleh masayarakan sebagai usaha Rumah tangga berskala mikro, kecil maupun menengah. Kota Padang sebagai ibu kota Provinsi Sumatera Barat memiliki usaha makanan yang cukup banyak. Salah satu usaha mikro yang ada di Kota Padang adalah Usaha Rakik Azizah yang dipimpin oleh Nur Afsah dan memiliki 4 orang karyawan. Usaha Rakik Azizah berlokasi di Jalan Koto Tuo RT 03/RW 04 Kelurahan Kapalo Koto Kecamatan Pauh Padang. Lokasi usaha berjarak sekitar $1 \mathrm{~km}$ dari kampus Unand.

Usaha Rakik Azizah merupakan usaha keluarga yang sudah dimulai sejak tahun 1987 tapi belum berkembang dengan baik. Jumlah produksi sekitar 13 gantang (26 kg) atau 75 kantong per hari. Satu kantong berisi 25 bungkus rakik maco dan 20 bungkus rakik kacang. Harga rakik kacang Rp.15.000/bungkus dan rakik maco Rp.12.000/bungkus. Saat ini pemasaran produk kelompok usaha ini masih terfokus di Kota Padang yaitu dititipkan di warung-warung dan dijual di pasar Bandar Buat. Kondisi produksi rakik Azizah dapat dilihat dari gambar-gambar berikut.
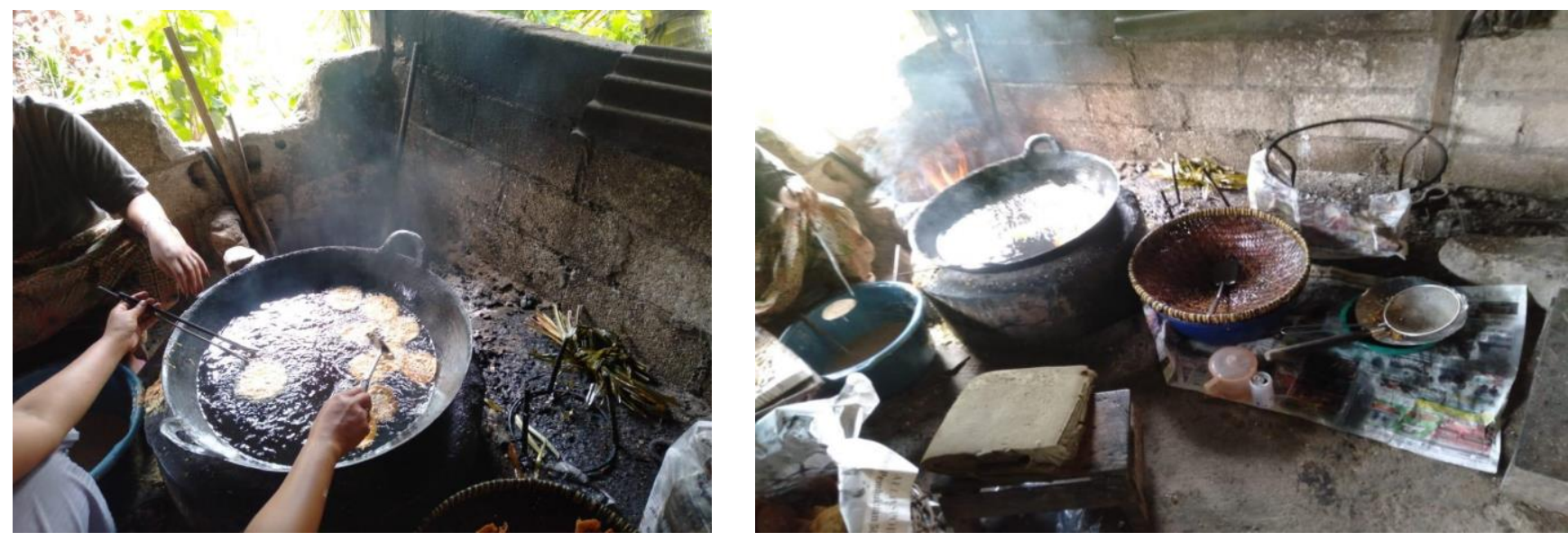

Gambar 1. Kondisi produksi rakik Azizah

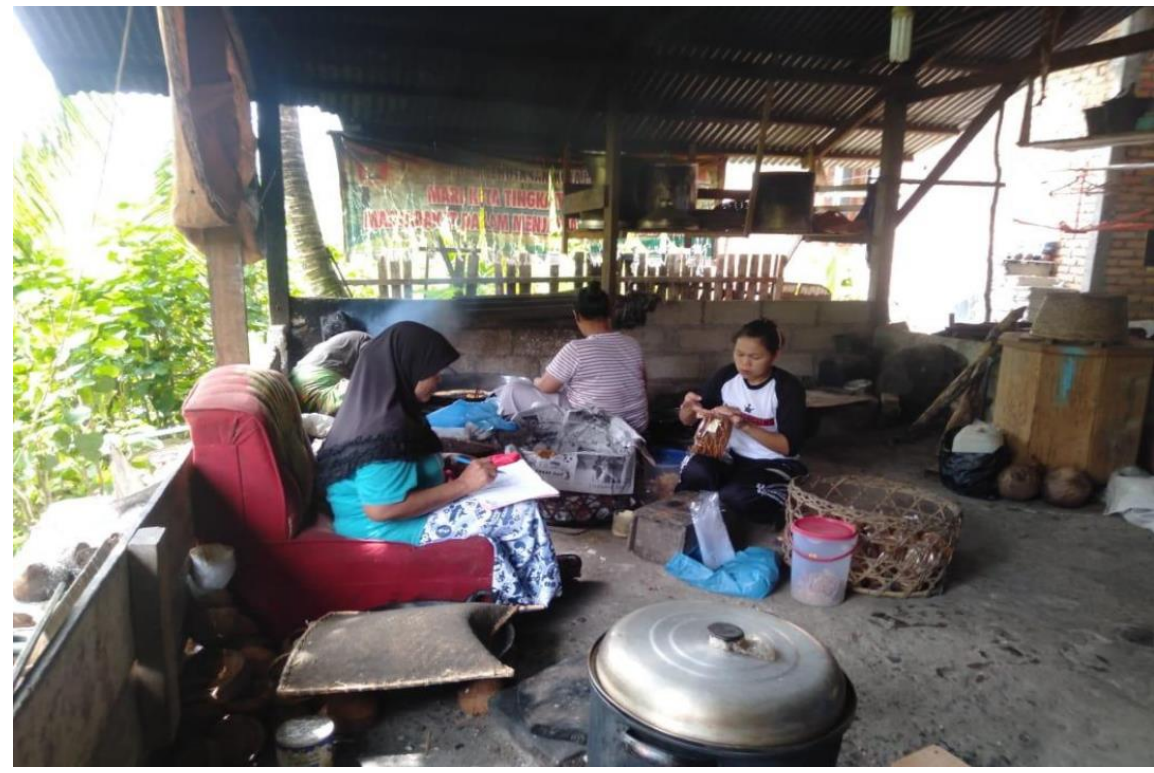

Gambar 2. Karyawan sedang melakukan rangkaian kerja untuk memproduksi rakik 
Usaha Rakik Azizah ini mempunyai potensi untuk berkembang karena rasa rakiknya cukup enak. Usaha Rakik Azizah ini walaupun berskala mikro namun mampu membuka kesempatan kerja terutama untuk kaum wanita (ibu rumah tangga dan remaja putri) dan diharapkan mampu meningkatkan pendapatan rumah tangga. Permasalahan utama yang ditemukan oleh Rakik Azizah ini adalah pemasaran. Kondisi ini akan mengakibatkan hambatan dalam pengembangan usaha dan kemampuan dalam merebut peluang pasar yang ada dan keberlanjutan usaha. Usaha Rakik Azizah masih mengandalkan penjualan secara tradisional dengan menitipan pada ritelritel atau distributor makanan ringan. Hal tersebut membuat kinerja penjualan usaha Rakik Azizah menjadi terbatas.

Disamping itu, kondisi kemasan dapat dilihat dari Gambar 3, masih seadanya dan tidak menarik, sehingga rasa produk yang enak terkesan tidak meyakinkan bagi konsumen. Pada kemasan belum tercantum P-IRT, karena belum memiliki izin dari Dinas Kesehatan Kota Padang. Hal ini akan menyebabkan kesulitan memasarkan produk ini ke pasar modern ataupun pemasaran on line. Dari kondisi ini, maka perlu dibina lebih lanjut agar usaha ini berkembang dengan baik. Penelitian Lita, Meuthia, \& Ma'ruf (2019) juga menemukan inovasi organisasi mempengaruhi kinerja usaha kecil. Selain itu, perlu juga mengembangkan UKM berbasis teknologi informasi baik untuk produksi, pemasaran maupun keuangan. Padahal, pemanfaatan teknologi dan sistem informasi dalam menjalankan industri kreatif dapat menjadi modal daya saing usaha tersebut untuk terus berkembang. Teknologi informasi menyebabkan perkembangan dan penyebaran industri kreatif, yaitu untuk menjangkau daerah geografis yang jauh karena efisiensi komunikasi dengan negara lain serta peluang pemasaran yang lebih luas.

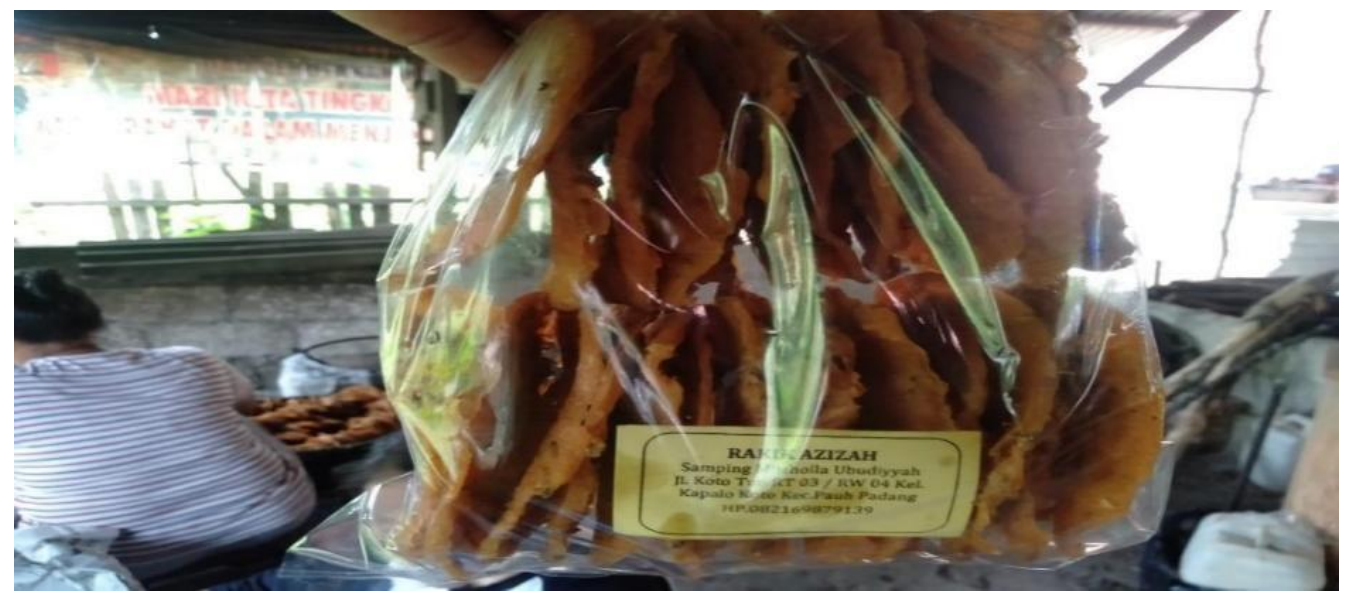

Gambar 3. Kondisi kemasan yang kurang menarik

Penelitian yang dilakukan oleh Agriqisthi \& Nasrah (2020) menemukan bahwa untuk membuat konsumen berminat membeli suatu produk perlu mengkombinasikannya dengan atribut lain seperti penerapan nilai-nilai konsumen. Sedangkan penelitian yang dilakukan oleh Lita, Meuthia, \& Faisal (2018). UMKM perlu memiliki nilai kreatifitas dan inovatif dalam menciptakan produk yang akan ditawarkan kepada calon pembeli. Kemudian penelitian Laužikas \& Mokšeckienė (2014) menambahkan bahwa apabila suatu bisnis memiliki nilai-nilai kreatifitas sehingga memiliki nilai tambah dalam menghadapi persaingan, bahkan memiliki kemampuan untuk memperluas pasar.

Berdasarkan hasil identifikasi di rumah produksi, maka ditemukan beberapa permasalahan utama yang dihadapi oleh mitra yaitu:

1. Bagaimana mengurus izin P-IRT usaha Rakik Azizah di Kota Padang?

2. Bagaimana inovasi kemasan usaha Rakik Azizah di Kota Padang?

3. Bagaimana pemasaran on line usaha Rakik Azizah di Kota Padang? 


\section{METODE}

Metode pendekatan yang digunakan dalam kegiatan pengabdian kepada masyarakat ini dapat dilihat pada Tabel 1.

Tabel 1. Metode pendekatan yang digunakan

\begin{tabular}{|l|l|l|}
\hline \multicolumn{1}{|c|}{ No } & \multicolumn{1}{|c|}{$\begin{array}{c}\text { Metode yang } \\
\text { Digunakan }\end{array}$} & \multicolumn{1}{c|}{ Keterangan } \\
\hline 1. & Metode ceramah & $\begin{array}{l}\text { Memberikan materi pelatihan tentang pentingnya memiliki izin } \\
\text { usaha, kemasan yang menarik dan pemasaran on line }\end{array}$ \\
\hline 2. & Metode praktek & $\begin{array}{l}\text { Praktek mengemas produk dan memasarkan on line dengan } \\
\text { Facebook, instagram, Whatsapps dan e-commerce lainnya }\end{array}$ \\
\hline 3. & Metode diskusi & Melakukan tanya jawab tentang materi pelatihan \\
\hline 4. & $\begin{array}{l}\text { Metode konsultasi } \\
\text { bisnis }\end{array}$ & $\begin{array}{l}\text { Pengrajin melakukan konsultasi tentang permasalahan yang } \\
\text { dihadapi dalam menjalankan usahanya kepada konsultan. Dalam } \\
\text { hal ini tim bertindak sebagai konsultan manajemen. Metode ini } \\
\text { akan membantu pengrajin dalam mencari solusi dari } \\
\text { permasalahan yang dihadapi, sehingga pengrajin mampu } \\
\text { mengambil keputusan yang tepat dalam pengembangan usaha }\end{array}$ \\
\hline 5. & Metode vokasi & $\begin{array}{l}\text { Melakukan pendampingan pada Rakik Azizah secara langsung } \\
\text { pada lokasi usaha setelah dilakukannya penyuluhan. } \\
\text { Memberikan pengetahuan serta pemahaman tentang } \\
\text { pengelolaan manajemen, kemasan, mengelola pemasaran digital } \\
\text { dan pengurusan izin usaha. i e }\end{array}$ \\
\hline
\end{tabular}

Sumber: Analisis penulis (2020)

Agar tujuan dari kegiatan pengabdian masyarakat ini tercapai yaitu pemilikian izin usaha, kemasan yang menarik dan pemasaran secara on line, maka perlu dibuat proses dan metode yang digunakan. Kegiatan pengabdian kepada masyarakat ini direncanakan berlangsung selama periode pelaksanaan kegiatan yang telah ditentukan dimana terdiri dari beberapa tahapan. Tahapan yang ada dalam kegiatan ini adalah sebagai berikut:

1. Tahap persiapan

Pada tahap ini pelaksana kegiatan melakukan pertemuan dengan pemilik usaha Rakik Azizah serta dosen yang berperan sebagai pemberi materi untuk menyampaikan tujuan kegiatan dan meminta persetujuan untuk melaksanakan kegiatan ini.

2. Tahap pelaksanaan kegiatan

Pada tahap pelaksanaan kegiatan dilaksanakan penyuluhan dan sosialisasi melalui metode ceramah, diskusi dan tanya jawab jika terdapat materi penyuluhan dan sosialisasi yang belum dimengerti oleh peserta.

3. Tahap pendampingan

Pada tahap ini pelaksana kegiatan akan melakukan pendampingan terhadap pemilik Usaha Rakik Azizah untuk membantu melaksanakan dan menerapkan materi-materi yang telah diberikan pada tahap sebelumnya. Tahapan pendampingan yang dilakukan adalah: 1) Mengevaluasi implementasi materi pada tahap 2, dan 2) Memberikan solusi terhadap permasalahan yang dihadapi saat implementasi.

\section{HASIL DAN PEMBAHASAN}

Pelaksanaan kegiatan pengabdian kepada masyarakat pada Usaha Rakik Azizah telah dilaksanakan pada tanggal 2 September 2020 yang diawali dengan melakukan observasi pada lokasi Usaha Rakik Azizah, kemudian meminta pemilik Rakik Azizah untuk diwawancara guna 
mengidentifikasi masalah-masalah yang dialami Rakik Azizah. Pada kesempatan yang sama pemilik Usaha Rakik Azizah diminta untuk menyepakati rencana kegiatan pengabdian yang akan dilakukan.

Selanjutnya tim kegiatan pengabdian melakukan rapat untuk mendiskusikan mengenai materi-materi yang dapat disampaikan guna memecahkan masalah yang dialami Usaha Rakik Azizah. Guna menerapkan physical distancing, maka rapat dilakukan menggunakan platform zoom pada tanggal 12 Oktober 2020. Pada saat rapat setiap anggota tim memberikan pandangan berdasarkan kepakaran masing-masing anggota tim. Sehingga ditetapkan topik yang relevan untuk diberikan adalah Manajemen Pemasaran dan Manajemen Keuangan. Pemilihan materi yang akan diberikan merujuk kepada kebutuhan permasalahan Usaha Rakik Azizah.

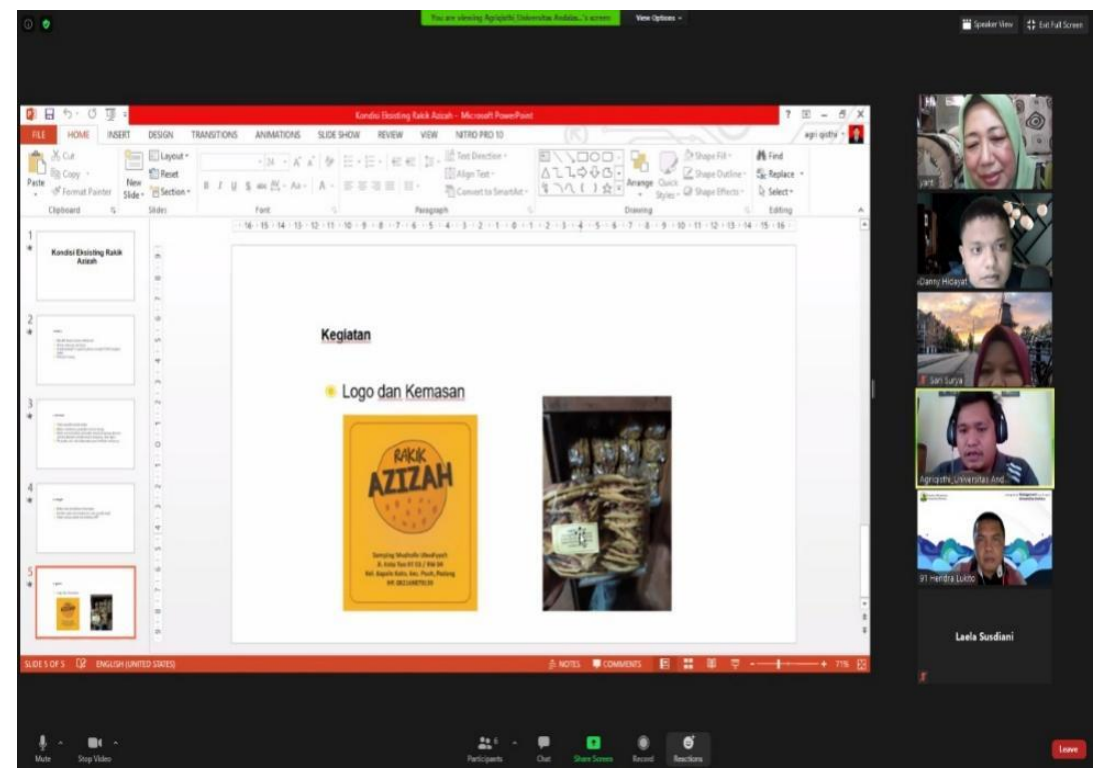

Gambar 4. Rapat Tim Kegiatan Pengabdian kepada Masyarakat

Kegiatan penyuluhan dilakukan pada tanggal 19 November 2020 di Jurusan Manajemen. Kegiatan menghadirkan pemiliki usaha Rakik Azizah dan juga beberapa Tim Teknis pelaksanaan pengabdian. Tim teknis nantinya akan menyampaikan materi kepada pemilik usaha. Pelaksanaan kegiatan dengan mengedepankan protokol kesehatan guna untuk memberantas penyebaran Covid-19, dan sebelum memasuki ruangan semua peserta wajib mengenakan masker dan mencuci tangan, serta pengaturan jarak minimal $1 \mathrm{~m}$ untuk setiap peserta.

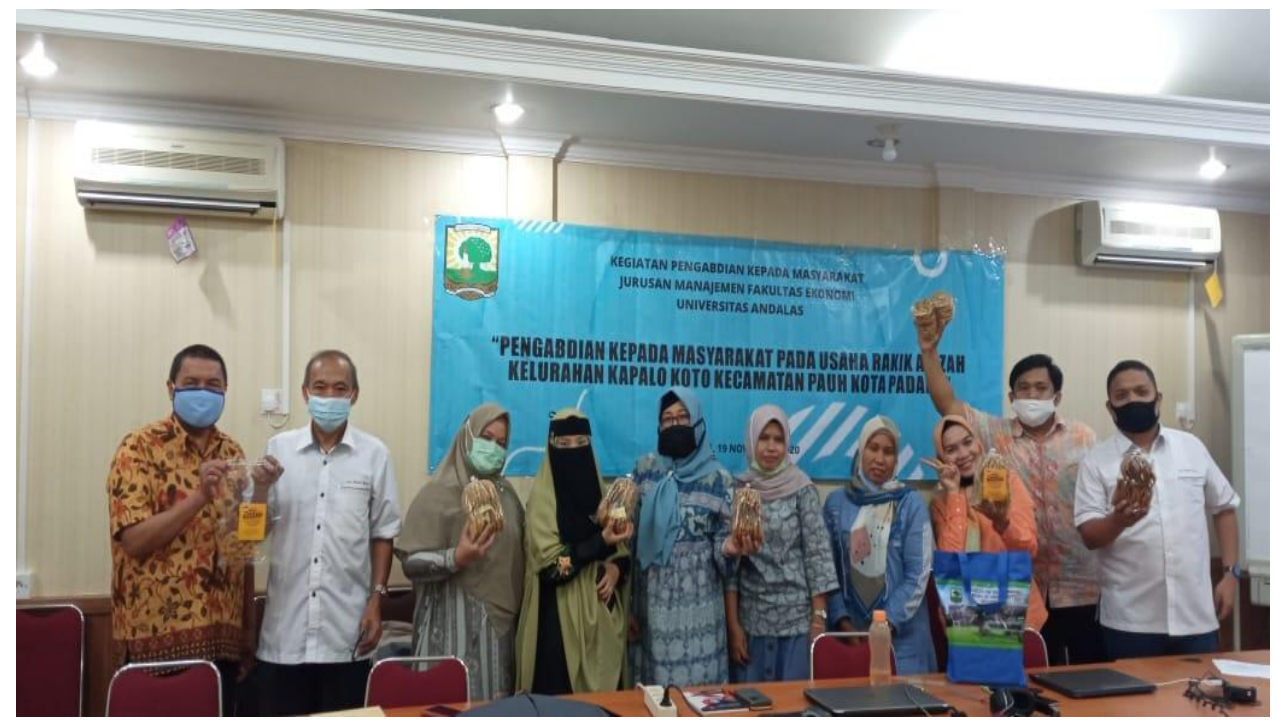

Gambar 5. Pelaksanaan Kegiatan Penyuluhan 
Penyuluhan disertai konsultasi perihal permasalahan yang dialami Usaha Rakik Azizah. Setelah penjelasan oleh pemilik Rakik Azizah tentang kondisi terkini Rakik Azizah maka dilanjutkan dengan diskusi berupa pertanyaan-pertanyaan yang diajukan oleh peserta penyuluhan. Diskusi yang dilakukan menyimpulkan bahwa adanya beberapa permasalahan atau kendala pada usaha Rakik Azizah, yaitu:

1. Kondisi penjualan Rakik Azizah cenderung tetap, dan sangat mengandalkan penjualan dengan menitipkan pada gerai-gerai dan agen.

2. Kemasan hanya mampu untuk diikat menggunakan gelang karet. Hal tersebut karena pada proses pengemasan harus rapat tidak ada celah agar tidak ada rakik yang pecah.

3. Belum mampu menjual keluar kota. Karena belum mendapatkan ekspedisi yang dapat menjamin produknya tetap utuh sampai di tujuan.

4. Produk termasuk yang gurih dan mudah patah. Hal tersebut yang menjadi alasan kenapa tidak menggunakan jasa kurir.

5. Label masih standar menggunakan kertas dan dimasukkan ke dalam plastik sehingga berminyak.

6. Pekerja hanya 3 orang, sehingga kapasitas produksi terbatas sesuai kemampuan saja.

Setelah melakukan penyuluhan, selanjutnya melakukan pendampingan yang dilakukan pada tanggal 26 November 2020 di lokasi produksi Rakik Azizah. Pendampingan dilakukan guna menerapkan materi-materi yang telah diberikan pada saat penyuluhan serta mempersiapkan berkas-berkas untuk pengurusan P-IRT. Pada saat kunjungan, pemilik sudah memulai melakukan pembukuan keuangan, sehingga dapat dikalkulasikan keuntungan dari Usaha Rakik Azizah. Selain itu pemilik sudah memahami betapa pentingnya memiliki izin usaha serta kemasan yang menarik. Pemilik sudah mampu membuat konten pemasaran pada sosial media dan dapat mempraktekkan bagaimana mengambil gambar produk yang akan diposting di sosial media seperti Facebook.

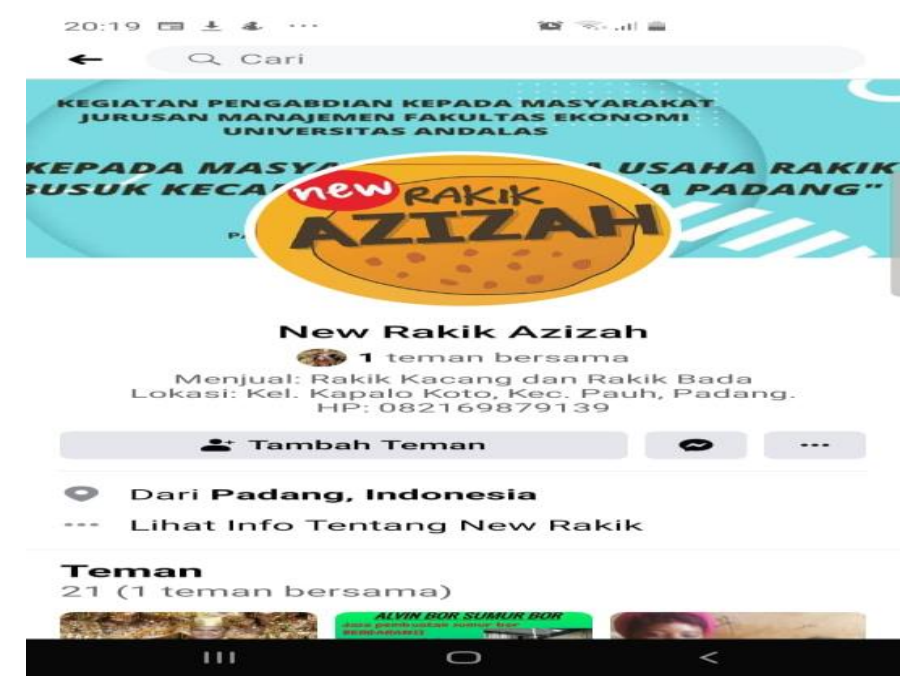

Gambar 6. Pemasaran melalui Media Sosial

Kendala yang dihadapi selama kegiatan adalah agak sulit merubah persepsi pengusaha Rakik Azizah untuk menghasilkan produksi yang lebih baik, perlu upaya dari tim pengabdi untuk meyakinkan pengusaha merubah persepsi mereka tentang pentingnya perbaikan kemasan dan melaksanakan pemasaran on line. Namun permasalahan ini bisa diselesaikan selama kegiatan pendampingan.

Keberlanjutan kegiatan ini dilakukan dengan membantu usaha Rakik Azizah mengurus PIRT dengan metode pendampingan. Pendampingan dilakukan dengan memberikan motivasi kepada pengusaha untuk mengembangkan pemasaran dan meyelesaikan pengurusan P-IRT sampai sertifikat keluar. 


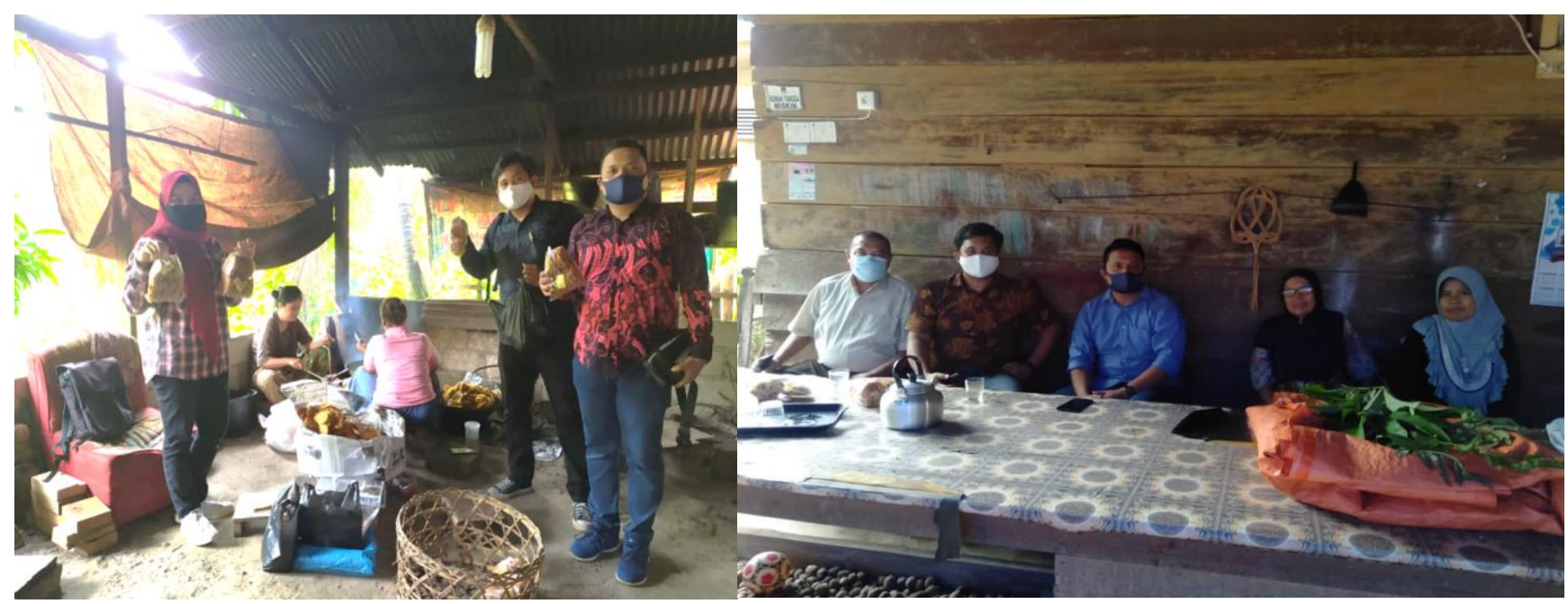

Gambar 7. Kegiatan Pendampingan di Lokasi Produksi Rakik Azizah

\section{KESIMPULAN}

Kesimpulan dari kegiatan pengabdian pada usaha Rakik Azizah yaitu:

1. Pentingnya memiliki P-IRT sebagai identitas usaha dan syarat administrasi untuk bisa mendistribusikan produk pada gerai-gerai besar.

2. Melakukan inovasi kemasan dengan merancang label baru (Rakik New Azizah) dan kemasan yang menarik.

3. Merancang pemasaran online dengan media sosial dan membuat program pemasaran. Pada kegiatan tersebut diberikan juga pemahaman tentang membuat konten promosi di sosial media. Pengusaha mampu untuk melakukan penjualan secara online.

\section{UCAPAN TERIMA KASIH}

Kegiatan ini dilaksanakan atas bantuan hibah pengabdian kepada masayarakat dengan dana Fakultas Ekonomi Universitas Andalas tahun anggaran 2020.

\section{DAFTAR PUSTAKA}

Agriqisthi, A., \& Nasrah, R. (2020). the Impact of Quality Perception and Value Perception Toward Purchase Intensity (Survey Coffee Shop Visitors in Padang City). Primanomics: Jurnal Ekonomi \& Bisnis, 18(2), 16. https://doi.org/10.31253/pe.v18i2.348

Laužikas, M., \& Mokšeckienè, R. (2014). The Development of Creative Industries: The Case of Lithuanian Fashion Design Companies. Societal Studies, 6(1), 34-66. https://doi.org/10.13165/sms-14-6-1-03

Lita, R. P., Meuthia, M., \& Faisal, R. F. (2018). Model Keterkaitan Market Orientation, Leadership, Organizational Innovation dan Organizational Performance pada Industri Kerajinan di Sumatera Barat. Jurnal Siasat Bisnis, 22(1), 38-61. https://doi.org/10.20885/jsb.vol22.iss1.art3

Lita, R. P., Meuthia, M., \& Ma'ruf, M. (2019). The Interrelated Model of Marketing Innovation, Market Performance, and Financial Performance at the Local Cuisines Shops in West Sumatera. Bilancia: Jurnal Ilmiah Akuntansi, 3(2), 220. Retrieved from http://www.ejournal.pelitaindonesia.ac.id/ojs32/index.php/BILANCIA/index 